\title{
BREATHING RATE/RHYTHM EVALUATION ASCERTAINS TOTAL HEALTH (BREATH): THE PULMONARY PANACEA
}

\section{R. Vinodh Rajkumar.}

Physiotherapist \& Anthropologist, Director - Prabhanjeet Fitness Research Institute OPC Private Limited, Bangalore, Karnataka, India.

\section{ABSTRACT}

Breathing orchestrates the homeostatic harmony. Well-balanced breathing pattern is a life-stabilizing and lifepropelling force. Adequate amount of oxygen intake mediates metabolism and brings meaning to life through coordinated activities of the anatomical and physiological marvels of the body. Though the body is equipped to withstand anaerobic conditions but it is only for restricted period of time based on the intensity of the physical activity, after which the oxygen must be replenished rapidly in extra quantities 'Oxygen debt' through increased rate of ventilation till the regulatory mechanisms of respiration restore the baseline breathing process. Oxygen intake is not the only role of lungs but to stringently defend against foreign organisms and eliminate $\mathrm{CO}_{2}$ also, including humidification of inhaled air. Thus, inherently lungs are unquestionably capable of protecting themselves and the whole body. Still, human errors could destroy the functions of lungs leading to excruciating morbidities. Some of these morbidities are even able to transform into exceedingly risky communicable diseases, therefore an infectious disease originating from just one individual might have potency to transmit across the globe. After the arrival of COVID-19, the entire world exhaustively struggles to understand the ways to protect the lungs or restore the functions of lungs to save people, obviously without knowing the status of respiratory fitness of every individual. Health of the lungs is controlled by several variables but all of them are inter-dependent to determine one common goal "rate and rhythm of breathing". This article aims to inculcate the practice of working in the direction of attaining and maintaining healthy respiratory cycles to prevent or cure the diseases.

KEY WORDS: Respiratory rate, Rhythm of breathing, Diseases of lung, Lung capacity, Chest expansion, Abnormal breathing pattern, Diaphragmatic breathing, Regulation of respiration.

Address for correspondence: R. Vinodh Rajkumar, Physiotherapist \& Anthropologist, Director Prabhanjeet Fitness Research Institute OPC Private Limited, Bangalore, Karnataka, India.

E-Mail: dreamofkalam@rediffmail.com

Access this Article online Quick Response code

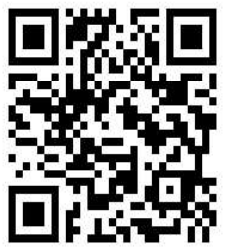

DOI: $10.16965 /$ ijpr.2020.161

Journal Information

International Journal of Physiotherapy and Research

ISSN (E) 2321-1822 | ISSN (P) 2321-8975

https://www.ijmhr.org/ijpr.html

DOI-Prefix: https://dx.doi.org/10.16965/ijpr

\section{Article Information}

Received: 26 Jul 2020

Peer Review: 27 Jul 2020

Revised: None
Accepted: 07 Sep 2020

Published (O): 11 Oct 2020

Published (P): 11 Oct 2020

\section{INTRODUCTION}

The first active effort to breath begins at the time of birth which is taken into account in APGAR score (Appearance, Pulse, Grimace, Activity and Respiration) and it is easy to interpret that the other components of APGAR depends upon that first respiration under the support of pulmonary surfactant. When air-breathing begins at birth, dispersion of air into surfactant-rich liquid of mature lungs results in formation of stable bubbles to establish immediate formation of functional residual capacity, continued gas exchange throughout the respiratory cycle, distension of saccules and saccular resistance to collapse as a result of the near-zero surface tension [1]. Though breathing is regarded as an unconscious function but precise and sustained interactions of neural, 
chemical and biomechanical regulations of respiration are essential for effortless breathing at rest and adequate breathing during different intensities of physical activity. Respiration creates both conscious and unconscious streams of rhythmic sensory inputs to the brain and this rhythmic activity modulates the temporal organization of cortical neurodynamics (cognitive, sensory and motor processes), thereby linking higher cortical functions (ongoing neuronal activity of the neocortex) to the process of breathing [2].

Unlike other skeletal muscles, the respiratory muscles cannot be strengthened directly through resisted exercises but still they can indirectly gain strength as they are naturally forced to work against the contraction of abdominal muscles (intra-abdominal pressure, hoop tension) or co-contract with the core muscles during various postures and intensities of physical activity. The main breathing muscle training is quite difficult because the breathing muscle is tiny and its position is complex but the core muscles (accessory muscles in respiratory system) are bigger and easier to design training [3]. By building intra-abdominal pressure, enhancing core stability and engaging in forceful exhalations during multiple postures of physical activities, the muscles of trunk (Abdominal muscles, Erector spinae, Latissimus Dorsi) also get strengthened concomitantly through multi-directional push/ pull activities using postures like squat, lunge, bend and twist. Needless to mention about the mobility and stability benefits derived by the thoracic cage (rib joints, thoracic vertebral column) through diverse postures and structured exercises which in turn will associate with measurable improvements in lung capacity (Spirometer test, Chest expansion test) and function ( $\mathrm{VO}_{2}$ max test, Exercise tolerance test). Multiple factors can lead to diminished or progressively deteriorating respiratory fitness which might require elaborate non-invasive and invasive assessments. Upper and lower chest expansion may be more useful in clinical practice to evaluate chest mobility and to give indirect information on lung function, but interpretation with caution is required when considering implementation into clinical setting [4].
Cirtometry is a reliable measurement of the circumference of the chest and abdomen taken during respiratory movements but it does not accurately measure pulmonary volumes measured by respiratory inductive plethysmography [5]. Spirometry is used in conjunction with a patient's history and physical examination to help evaluate lung function and assist in diagnosing or monitoring different categories of lung disease [6]. Peak expiratory flow rate (PEFR) is a person's maximum speed of expiration, an effort-dependent parameter, emerging from the large airways within about $100-120$ msec of the start of forced expiration and it measures the degree of obstruction in the airways [7].

Conventional spirometric techniques involving pneumotachometers record respiratory flow and calculate tidal volumes, however, the use of a mouthpiece may alter normal respiration patterns but Respiratory Inductive Plethysmography (RIP), which includes two belts, one thoracic and one abdominal, is able to determine spontaneous tidal breathing without the use of a facemask or mouthpiece [8].

Auscultation is one of the first examinations that a patient is subjected to in a General Practitioner's office, especially in relation to diseases of the respiratory system and it is a highly subjective process that depends on the physician's ability to interpret the sounds as determined by his/her psychoacoustical characteristics potential enough to lead to inaccurate diagnosis and mistreatment [9]. The chest radiograph (CXR) is the most commonly used diagnostic imaging modality [10]. Airway endoscopy will remain critical in the evaluation of bronchopulmonary diseases due to their increase in diagnostic yield and minimal risk [11]. Computed tomography-guided percutaneous needle biopsy of the lung is an indispensable tool in the evaluation of pulmonary abnormalities due to its high diagnostic accuracy in the detection of malignancy thus playing a critical role in obtaining pathologic proof of malignancy, guiding staging and planning treatment [12].

Individuals can be on different points on lung health and lung disease (i) No lung disease with optimal lung (ii) No lung disease with poor lung health (iii) Lung disease with preserved lung health and (iv) Lung disease with poor lung 
health [13]. Dealing with the continuum of respiratory health and diseases is highly complicated despite the availability of wide range of invasive and non-invasive technologies for assessments and treatments. Lesser mortals and clinicians must contend with deviations from the normal arc, and consensus thresholds for normality and the diagnosis of disease [13].

Nevertheless, the fundamentals in the health care must be strong, never neglected and routinely revisited for making further refinements. Respiratory rate (RR) is a vital component of clinical assessment and monitoring but current methods of RR assessment by doctors are inaccurate, significantly delaying appropriate clinical care or even misguiding treatment [14]. Respiratory rate measurement is regarded as a core nursing skill, yet there are numerous recorded discrepancies in the monitoring and assessment of patients' respiratory rate [15].

The level of documentation of vital signs in many hospitals is extremely poor, and respiratory rate, in particular, is often not recorded [16]. To assess the risk of imminent respiratory failure, clinical evaluation should give emphasis to respiratory rate, work of breathing, use of accessory musculature, and skin perfusion [17]. Assessment of respiratory rate and rhythm is crucial in diagnosis and clinical decision making because patients would present different breathing patterns due to various direct and indirect diseases influencing the lungs. Not only in the disease states, in general, even in the apparently healthy state, individuals tend to have unique breathing patterns controlled by several variables. Understanding of individuals' respiratory rate should be given prime importance to define the state of health and disease, and in fact, the basics of breathing rate and rhythm (at rest, during exercise, in disease circumstances) should be thoroughly researched to be regarded as the simple yet the most inevitable credible indicators of overall health. The purpose of this article is to stimulate interdisciplinary and transdisciplinary approaches to revisit and investigate the basics of breathing rate and rhythm to an extent of simplifying this basic vital sign predominantly as a self-diagnostic tool to ascertain harmoni- ous homeostasis.

\section{DATA COLLECTION AND INTERPRETATION}

In the contemporary scenario, the infrastructure for structured supervised exercise training does not facilitate or render scopes for elaborate assessment of fitness components and interdisciplinary approach to holistic health. Few Physiotherapists who solely rely on exercisebased approaches, endeavour (using the limited infrastructure) to assess in detail to understand the physique, baseline functional status and progressions of their clientele. The data in Table 1 to 7 , shows the value of breathing rate of few men and women in association with several other variables. During the assessment, none of them were instructed to emphasize on breathing but to remain quiet for one minute. Breathing rate was counted for one minute through visual observation of the chest wall or gentle torso motions when the individuals were in sitting posture and quietly breathing. Radial pulse was also counted for one minute in the same sitting posture, with the forearm comfortably rested on the bench at chest level. Fat \% was assessed by skin fold thickness test ( 7 sites for men, 3 sites for women). Heath-Carter anthropometric somatotype test was applied to evaluate the endomorphy, mesomorphy and ectomorphy scores. Blood pressure was manually assessed with the help of sphygmomanometer and stethoscope. They were all tested on different days based on the time of their enrolment/subscription to supervised exercise trainings.

Table 1: All four men were Mesomorphic Endomorphs at the time of assessment.

\begin{tabular}{|c|c|c|c|} 
Male & $\begin{array}{c}\text { Somatotype Score } \\
\text { (Endomorph:Mesomorph:E } \\
\text { ctomorph) }\end{array}$ & $\begin{array}{c}\text { Breathing rate } \\
\text { at rest }\end{array}$ & $\begin{array}{c}\text { Pulse rate } \\
\text { at rest }\end{array}$ \\
\hline A & $\begin{array}{c}\text { 6.2: } 4: 1.5 \\
\text { B }\end{array}$ & 12 & 64 \\
\hline C & $8.9: 3.7: 1.6$ & 18 & 61 \\
\hline D & $8: 4.3: 1.1$ & 12 & 66 \\
\hline
\end{tabular}

Table 2: Continuation of data of four men as shown in Table -1 .

\begin{tabular}{|c|c|c|c|c|}
\hline Male & Age (Years) & Weight (Kg) & Height (cm) & Fat\% \\
\hline A & 41 & 74 & 173 & 22 \\
\hline B & 45 & 80 & 177 & 30 \\
\hline C & 35 & 70 & 166 & 26 \\
\hline D & 50 & 69 & 168 & 28 \\
\hline
\end{tabular}


Table 3: Women A, B and C were Mesomorphic Endomorphs and Woman D belonged to Ectomorphic Endomorph at the time of assessment.

\begin{tabular}{|c|c|c|c|}
\hline Female & $\begin{array}{c}\text { Somatotype Score } \\
\text { (Endomorph:Mesomorph:E }\end{array}$ & $\begin{array}{c}\text { Breathing rate } \\
\text { at rest }\end{array}$ & $\begin{array}{c}\text { Pulse rate at } \\
\text { rest }\end{array}$ \\
\hline ctomorph) & & \\
\hline B & $11.6: 5: 0.1$ & 17 & 72 \\
\hline C & $8.8: 3.6: 2.2$ & 19 & 64 \\
\hline D & $11.5: 4.7: 0.3$ & 15 & 67 \\
\hline
\end{tabular}

Table 4: Continuation of data of four women as shown in Table -3.

\begin{tabular}{|c|c|c|c|c|}
\hline Female & Age (Years) & Weight (Kg) & Height $(\mathbf{c m})$ & Fat\% \\
\hline A & 38 & 69 & 157 & 40 \\
\hline B & 28 & 54 & 157 & 30 \\
\hline C & 46 & 66 & 153 & 42 \\
\hline D & 30 & 52 & 167 & 29 \\
\hline
\end{tabular}

Table 5: 40 years old male. Able to reach 400 meters on treadmill at $12.5 \mathrm{Km} / \mathrm{h}$. Height $=172 \mathrm{~cm}$. Weight $=94 \mathrm{Kg}$. Fat $\%=32 \%$. Cooper's 12 minutes run test performance $=1.42 \mathrm{Km}$ with $\mathrm{VO}_{2} \max =20.46 \mathrm{ml} / \mathrm{Kg} / \mathrm{min}$ (Below average). Sprint pace $=17.7 \mathrm{Km} / \mathrm{h}$. Standing long jump $=190 \mathrm{~cm}$.

\begin{tabular}{|c|c|c|c|} 
Date of Assessment & $\begin{array}{c}\text { Breathing rate } \\
\text { at rest }\end{array}$ & $\begin{array}{c}\text { Pulse rate } \\
\text { at rest }\end{array}$ & $\begin{array}{c}\text { Blood pressure } \\
\text { at rest }\end{array}$ \\
\hline 17.06 .2019 & 14 per minute & 84 per minute & $130 / 90 \mathrm{mmHg}$ \\
\hline 30.08 .2019 & 8 per minute & 68 per minute & $110 / 75 \mathrm{mmHg}$ \\
\hline 17.02 .2020 & 12 per minute & 75 per minute & $110 / 75 \mathrm{mmHg}$ \\
\hline
\end{tabular}

Table 6: 73 years old male (Mesomorphic Endomorph) under medications with history of seizure and memory difficulties. Height $=167 \mathrm{~cm}$. Weight $=63 \mathrm{Kg}$. Fat $\%=31$. Difficulty to control thoracic kyphosis in sitting, standing and walking postures.

\begin{tabular}{|c|c|}
\hline Somatotype & $6.3: 4: 2$ \\
\hline Breathing rate at rest & 17 per minute \\
\hline Pulse rate at rest & 74 per minute \\
\hline Blood pressure at rest & $140 / 70 \mathrm{mmHg}$ \\
\hline
\end{tabular}

Table 7: 45 years old male (Mesomorphic Endomorph) under medications with history of cardiac surgery for myocardial infarction. Height $=177 \mathrm{~cm}$. Weight $=70 \mathrm{Kg}$. Fat $\%=28.5$. Cooper's 12 minutes run test $=1.35 \mathrm{Km}$ with $\mathrm{VO}_{2} \mathrm{max}=18.89 \mathrm{ml} / \mathrm{Kg} / \mathrm{min}$ (Below average). Sprint pace $=20.5 \mathrm{Km} / \mathrm{h}$. Standing long jump $=220 \mathrm{~cm}$.

\begin{tabular}{|c|c|}
\hline Somatotype & $7.6: 4: 2.5$ \\
\hline Breathing rate at rest & 14 per minute \\
\hline Pulse rate at rest & 56 per minute \\
\hline Blood pressure at rest & $90 / 60 \mathrm{mmHg}$ \\
\hline
\end{tabular}

By just looking at these data, it is not possible to identify and accredit anyone as the healthiest person or the most unfit person. All these individuals were differing a lot in their body composition, height, functional capacity, functional limitations, exercise history, lifestyle and medical history, apart from the age-related differences and immeasurable differences in their mental health. For example, the individual in table- 5 had shown a drop in the blood pressure values after including exercises as a part of his life, without the help of medicines. But same reduced blood pressure values were found associated with his different breathing and pulse rates, therefore it still needs a confirmation from an interdisciplinary team about which of the breathing and pulse rate combinations associated with the drop in his blood pressure can be considered as a sign of improvement.

Individual in table-6 showed tendencies of thoracic kyphosis in various postures but he was able to rectify this postural deviation only for a transient period based on repeated corrective instructions of therapist. He could not exercise under the supervision of the Physiotherapist for about 4 months due to his travel which probably had led to another episode of seizure and hospitalization. Such defective postures can affect the work of breathing muscles and, the effectiveness of posture correction on breathing rate and its associated variables can be researched as a longitudinal study. Individual in table-7 was exhibiting athletic characteristics even after undergoing cardiac surgery for myocardial infarction six months ago, but the medications to lower his blood pressure create difficulty to interpret if his breathing and pulse rates were in healthy range or not.

Interestingly the cardiac surgery patient in table7 displayed better performances in sprint and standing long jump than the apparently healthy individual in table-5. Woman A and D in table- 3 displayed almost similar breathing rate and pulse rates though they belonged to different somatotypes, age group, fat \%, weight and height. Apart from the variables shown in the tables 1 to 7, multiple other variables (anthropometry, biochemical, pulmonary function tests) can be taken into account to study the basics of respiratory rate.

Interpretations widen and ramify as the number of variables increase in the explorations to establish their correlations with normal and abnormal breathing patterns. If this level of data could be collected availing limited infrastructure by one Physiotherapist, massive amount of data 
collection is possible with the support of advanced technologies and interdisciplinary investigations to excavate the physiological facts of healthy breathing mechanisms. Why we must accentuate the scientific investigations on the fundamentals of breathing rate?

\section{DISCUSSION}

Earliest asymptomatic biomechanical dysfunctions of unhealthy ageing could begin before or during adolescence [18]. Similarly, asymptomatic dysfunctions in respiratory system could also begin in early life but the affected individuals will give the impression of a healthy state. Such asymptomatic respiratory dysfunctions could encompass (i) reduced strength of respiratory muscles (ii) reduced mobility of thoracic column and ribs with or without postural deviations (iii) reduced lung capacity, aerobic capacity and exercise tolerance and (iv) reduced depth and irregular rhythm of breathing. Currently, though we have adequate technology, assessments of respiratory system are not completely interdisciplinary, so various respiratory dysfunctions will remain unnoticed rendering scopes for maturation of diseases. For instance, the tests for exercise tolerance, aerobic capacity, chest expansion and mobility of thoracic spinal column should be ideally conducted by Physiotherapists but needless to mention that these diagnostic procedures have not yet received the deserved acceptance and incorporation into the clinical practice like period health check. Multi-phasic test, also known as Master Health Checkup (MHC) is useful in detecting and identifying diseases or the warning signs of an impending disease in advance, also enabling health care providers to assess health risks and advise the patients on lifestyle modifications to counter such risks [19]. In contrary to this, serious of attempts are usually made only after any disease matures almost irreversibly. Sustained dysfunctional breathing (DB), or faulty breath patterns, likely develops as a maladaptive coping response to real or perceived environmental stressors [20]. Such stressors could impair the breathing rate and rhythm of apparently healthy individuals due to neurological or metabolic or biomechanical disturbances before even they start to affect the health of the individuals or become identifiable in clinical examinations. Respiratory function relies on conscious and unconscious sensory signals. Consciously accessible sensations of normal, unobstructed breathing include odor perception, the mechanical and thermal sensation of air flowing through nose, mouth, upper airways, and the proprioception of movements of the chest and abdomen and, unconscious sensory signals caused by respiration include interoceptive signals from the lungs, diaphragm and internal organs, which represent the mechanical consequences of respiratory movements, and the chemosensitive signals from the cardiovascular system, which represent breath-by-breath fluctuations of $\mathrm{CO}_{2}$ and $\mathrm{O}_{2}$ levels in the blood [2].

The maladaptive coping response to stressors, in addition to lack of breathing practice and adequate attention to personal health, could lead to dysfunctional breathing rate and rhythm during awakened or sleep states, perhaps even mimicking Cheyne-Stokes breathing, Biot's breathing and Kussmaul's breathing. CheyneStokes respiration is a specific form of periodic breathing (waxing and waning amplitude of flow or tidal volume - hyperventilation) characterized by a crescendo-decrescendo pattern of respiration between central apneas or central hypopneas [21]. Biot's breathing occurs when periods of apnoea alternate irregularly with series of breaths of equal depth that terminate abruptly, and is associated with meningitis [22]. Kussmaul's respiratory sign is usually present in patients with acidosis due to Diabetes or uraemia [23]. Diabetic ketoacidosis (DKA) associated with several metabolic and electrolyte derangements (hypokalemia, hypomagnesemia, hypophosphatemia) can ultimately result in tachypnea and failure of respiratory muscles failure [24].

The perspective that the apparently healthy individuals might be having any of these abnormal respirations' cannot be straightaway disqualified because individuals tend to lead an unhealthy lifestyle based on the environmental influence (malnutrition, sedentary state, substance abuse, disordered sleeping, malicious emotions), hence it must be only verified through clinical examinations and researches. 
The intolerable crisis caused by COVID-19 has unveiled the setbacks caused by lack of sufficient information about the victims' earlier respiratory health particularly in terms of pulmonary function tests, cirtometry, aerobic capacity, exercise tolerance and, breathing rate and rhythm. Therefore, the treatments and rehabilitations will be forced to progress without definite objectives. It is thought-provoking to analyse the productivity of clinical decision making which are urgently made without any past data about the respiratory health of the individuals. $70 \%$ to $80 \%$ of the morbidity and mortality occurring in the perioperative period is associated with some form of respiratory dysfunction [25].

Accurate knowledge of anatomy and physiology of the respiratory tract is important not only in the field of pulmonology but also in anaesthesiology and critical care because various anaesthetic drugs alter neuronal control of the breathing and bronchomotor tone [26]. "Mechanical ventilation (in and of itself) does not produce lung healing; it merely keeps patients alive until their own biological mechanisms are able to outwit the coronavirus. Never before in 45 years of active practice have I witnessed physicians coping with inadequate medical resources-specifically a shortage of ventilators. Given this situation, it is pivotal that caregivers have the requisite knowledge to interpret arterial oxygenation scientifically, know when to institute mechanical ventilation, and equally know how to remove the ventilator expeditiously to make it available for the next patient. Respiratory rates of 25-35 breaths per minute should not be viewed as ipso facto (knee jerk) justification for intubation, but rather the expected physiological response to lung inflammation" [27]. In patients with chronic compensated respiratory disease and acidosis, an acute insult such as pneumonia or disease exacerbation can lead to ventilation/perfusion mismatch, if severe enough, increased intracranial pressure and papilledema may ensue, increasing the risk of herniation and possibly even death [28].

Restoration of respiratory functions is the key objective in various clinical and surgical conditions and, among all, enabling proper and sufficient breathing at rest should be the prime goal because various physiological functions depend on it. The National Institute for Clinical Excellence (NICE) state that RR is the most sensitive marker of a deteriorating patient and the first observation to indicate a problem [29]. "The normal respirophasic effects of chest mechanics on blood pressure occur due to changes in intrathoracic pressure, right heart filling, radial traction on the pulmonary vasculature, decreasing blood flow to the left heart and cardiac output, all leading to decrease in systolic pressure during inspiration and the opposite occurs during expiration. The depth of respiration influences the magnitude of pulsus paradoxus and will be amplified in patients with pulmonary disease, so the patients should not be instructed to change their breathing pattern" [30].

"Respiratory muscle strength was not impaired, either before or two months after cardiac surgery (median sternotomy) but altered respiratory movements, distortion of the chest wall configuration and the reduction of the chest wall compliance might be one explanation for the decreased lung function found two months after surgery. In the last decade breathing exercises aimed to influence respiratory muscle strength have been introduced in treatment of patients subjected to cardiac surgery" [31]. Pulmonary function tests (PFTs) provide objective, quantifiable measures of lung function and are used to evaluate and monitor diseases that affect heart and lung function, to monitor the effects of environmental, occupational, and drug exposures, to assess risks of surgery, and to assist in evaluations performed before employment or for insurance purposes [32]. Postoperative lung function gradually recovers, but even months after surgery a reduction of $6-13 \%$ of preoperative spirometry has been reported [33]. The lack of the baseline PFT results prior to the illness (COVID - 19) make it difficult to make a comparison with the results after the illness and also the association between CT image and the lung function parameter wasn't analysed in our study [34].

Taking all these wide range of risks and concrete empirical evidences into account, is it not important to include different types of tests 
for respiration (preferably in $\mathrm{MHC}$ ), so that the clinical decision making will become more interdisciplinary, safe and productive? Every speciality in the interdisciplinary team will have domain-specific profound knowledge garnered through extensive practical experience, hence the flow of plans from different relevant experts ultimately finalizes the clinical outcomes. Several decades of research literatures are currently available to understand everything about the basics and the cutting-edge science and technology pertinent to respiratory system but COVID-19 has been still enigmatic and devastative. Perhaps, revisiting and refining the fundamentals could (i) prevent or resolve any type of pulmonary disease (ii) reveal the simplest techniques to recover or improve the functions of respiratory systems as early as possible.

The relative contributions of the rib cage and abdomen to ventilation were studied in the sitting position in patients with ankylosing spondylitis and in various patients the vital capacity and total lung capacity were reduced, but functional residual capacity was normal and the findings are consistent with a reduced mobility of the ribs and a greater than normal excursion of the diaphragm during breathing [35]. In fitness evaluations, it is possible to find several individuals (without any diagnosed disorder like ankylosing spondylitis) having inflexibility of the musculoskeletal system including the stiffness of the vertebral column, so reduced mobility of ribs and greater excursion of the diaphragm during breathing could be an unnoticed dysfunction among them also. Many seemingly healthy individuals display very weak lower limb strength and neuromuscular control, so their strategy of getting up from the floor almost resemble Gower's sign of Muscular dystrophy [36].

This has been an interesting aspect in the field of fitness testing and exercise prescription for general population who tend to exhibit some type of clinical feature of a disease though that disease is absent in them. Walking without arm swinging as in Parkinson's disease, painless yet inflexible dominant shoulder (mostly right shoulder) restricting the reach of hand to the contralateral scapular region as in Frozen shoulder, are the other best examples of asymptomatic constraints that simulate clinical features of some disorders. Similarly, many such asymptomatic respiratory dysfunctions (mechanical, neurological, biochemical) could exist, thus deserves scientific probing. The function of respiration is beyond the lifesupporting exchange of gases towards a link between the states of the body and mind" [2].

Variety of therapies to heal or maximize the lung functions can be derived from breathing and mind-control exercises. Breathwork is used to describe a host of spiritual, psychological, and medical practices and interventions that amount to numerous conscious, intentional and voluntary breath-related exercises as opposed to unattended, reflexive, and autonomic and, future researchers should examine how breath-related interventions affect psychological distress, including anxiety and alexithymia as outcome variables [37]. Breathing practice, also known as "diaphragmatic breathing" or "deep breathing," involves contraction of the diaphragm, expansion of the belly, and deepening of inhalation and exhalation, which consequently decreases the respiration frequency and maximizes the amount of blood gases and evidences demonstrate the ability of diaphragmatic breathing (6 diaphragmatic breaths / $\mathrm{min}$ protocol) to improve sustained attention (cognitive function), affect (negative emotion), and physiological response to stress (cortisol levels) by predominantly exerting its influence on the autonomic nervous system [38].

Regular practice of singing may improve QoL (Quality of Life), and preserve the maximal expiratory pressure (PEmax) of COPD patients by causing to "desensitization" of breathlessness as it involves strong and fast inspirations, followed by extended, regulated expirations and an accurate control of breathing [39]. Dance is one of the special forms of exercise which has a wholesome effect on the human body and the practice of regular Bharatanatyam dance will be beneficial in improving pulmonary functions and respiratory efficiency [40]. It is understandable based on research data that the respiratory system is capable of fighting against any illnesses but it also relies on disciplined efforts of the humans during appropriate stage in life 
in order to retain or enhance the respiratory fitness for healthy ageing, before any irreversible deterioration occurs. Loss in pulmonary function may lead to ventilatory limitation in exercise in the active elderly, limiting the ability to accrue the health benefits of physical activity into senescence [41]. Immune response within the respiratory tract follows an ordered, stepwise program of engagement of distinct tiers of defense [42]. Alcohol intake also seems to be related to a higher frequency of pneumonias by adversely affecting the respiratory and immune systems to alter the mechanism of respiratory clearance (depression of the glottic reflexes: glottis, cough, and ciliary action), and smoking has also been reported to be a residual confounding factor in studies of associations between oral conditions and respiratory infections [43].

Bacteria from the oral biofilms may be aspirated into the respiratory tract to influence the initiation and progression of systemic infectious conditions such as pneumonia but improved oral hygiene has been shown to reduce the occurrence of nosocomial pneumonia, both in mechanically-ventilated hospital patients and non-ventilated nursing home residents [44]. The decreased functional residual capacity and expiratory reserve volume, with a high closing volume to functional residual capacity ratio of obesity, are associated with the closure of peripheral lung units, ventilation to perfusion ratio abnormalities and hypoxemia, especially in the supine position [45]. No statistically significant difference in the pulmonary function test in the two groups (apple shaped, pear shaped) was found but there is a possibility of subclinical reduction in pulmonary function more in apple shaped than in pear shaped individuals [46].

Tons of existing research findings and the empirical evidences indicate the necessity of preserving optimal lung functions and the most fundamental of all is the breathing mechanism (rate and rhythm). Breathing cycles perform many functions apart from gaseous exchange like cellular metabolism, pulsus paradoxus, resisting infections, influencing autonomic nervous system, exercise tolerance ( $\mathrm{VO}_{2} \mathrm{max}$ ), cognitive functions, and also get influenced by multiple factors like postures, somatotype (body shape, fat distribution and musculoskeletal robustness), strength of respiratory muscles, atmospheric pressure, nutritional status and many more. It will be beneficial if the research and clinical practice emphasizes on discovering individualspecific perfect breathing rate and rhythm and, eliminating all the risk factors (substance abuse, occupational hazards) sabotaging this foundation of respiratory system. In general, it is often impractical to learn all the precautions and rectifications after allowing the diseases to an irreversible state and, additionally, each individual also develops unique combination of clinical features or morbidities. Human physique and functional capabilities are highly complex on account of unlimited intra-somatotype and inter-somatotype variations [47].

The mortality rates could rapidly surge globally if the communicable and non-communicable diseases meet and strongly interact perfectly at one point as 'Epidemiological Intersection' [48]. There is always an inevitable relationship between diminishing physical capacity and almost all the diseases, caused by gravitational torque deficiency [49]. It is also vital for humans to evolve as spiritually intelligent beings to avoid harming the self or others, so that the human mind and body remains integrated to be serene, disease-free and, competent enough to overcome various stressors independently or as a team (interdisciplinary, transdisciplinary). Spiritual Intelligence helps to fulfill the potentialities of the individuals' abilities through the non-cognitive virtues to prepare them to solve the everyday problems for life creatively and constructively in the new situation of the socio-psycho-physical environment for attaining the highest knowledge and wisdom [50].

\section{CONCLUSION}

Breathing cycles must be smooth tides on which the major proportion of life should sail without facing any turbulence. Well-balanced breathing pattern is a life-stabilizing and life-propelling force. Assessment of breathing rate and rhythm should never be neglected or done imprecisely in clinical diagnosis, MHC and fitness evaluations. Recommendations to attain/ preserve optimal breathing rate and 
rhythm shall include (i) Practicing deep diaphragmatic breathing exercises and avoiding any other form of rapid breathing exercises in resting state (ii) Enhancing postural awareness (iii) Improving flexibility of whole musculoskeletal system, especially the thoracic column mobility, using different variations of stretching exercises (iv) Exposures to anaerobic exercise zones and exercise-induced breathing stresses to equip the body to tolerate the fluctuations in arterial blood gases and metabolism in disease states ( $v$ ) Integrating multiple types of resisted exercise techniques to indirectly develop strength and fatigue-resistance in respiratory muscles (vi) Maintaining hygiene of upper and lower respiratory tract to retain the protective functions of lungs against microorganisms and pollutants (vii) Investigating the breathing patterns and capacities of the healthy individuals (both at rest and during exercise) and setting functional benchmarks, so that the patients also can dutifully work towards them abstaining from unhealthy habits (vii) Interdisciplinary efforts to incorporate Cirtometry, Breathing pattern assessment, Spirometry and establishing their correlations with other vital signs like heart rate and blood pressure, to track the impact of diseases, therapies, somatotypes, lifestyle modifications and ageing (viii) Singing and dancing habits can be inculcated or included whenever feasible and found relevant (ix) Never underestimate the non-communicable diseases as they could interfere with the biomechanical or neurological or chemical regulation of respiration, due to the underlying pathology and polypharmacy $(x)$ Focusing on the development of spiritual intelligence.

COVID-19 has unveiled the limitations of health care system, despite the fact that each sub- discipline of the medical field has attained peak advancements in their respective domains, in obstructing the spread of respiratory tract infections and its associated multifaceted complications. It is high time to refine the paradigms of health, lifespan and all medical approaches to revolve around 'Pulmonary panacea'.

\section{Conflicts of interest: None}

\section{REFERENCES}

[1]. Scarpelli, E.M. Perinatal lung mechanics and the first breath. Lung 1984;162:61-71.

https://doi.org/10.1007/BF02715632

PMid:6371391

[2]. Heck DH, McAfee SS, Liu Y, Babajani-Feremi A, Rezaie R, Freeman WJ, Wheless JW, Papanicolaou AC, Ruszinkó M, Sokolov Y and Kozma R (2017) Breathing as a Fundamental Rhythm of Brain Function. Front. Neural Circuits 10:115. https://doi.org/10.3389/fncir.2016.00115 PMid:28127277 PMCid:PMC5226946

[3]. Ashira Hiruntrakul. The Effect of Core Muscle Strength Training on Lung Function Middle and Long Distance Athletes. J J Sport Med. 2018;5(1):024.

[4]. Ravi S. Reddy, Khalid A. Alahmari, Paul S. Silvian, Irshad A. Ahmad, Venkata Nagaraj Kakarparthi, and Kanagaraj Rengaramanujam. Reliability of Chest Wall Mobility and Its Correlation with Lung Functions in Healthy Nonsmokers, Healthy Smokers, and Patients with COPD. Canadian Respiratory Journal Volume 2019, Article ID 5175949, 11 pages. https://doi.org/10.1155/2019/5175949

PMid:30931074 PMCid:PMC6410441

[5]. Caldeira Vda S, Starling CC, Britto RR, Martins JA, Sampaio RF, Parreira VF. Reliability and accuracy of cirtometry in healthy adults. J Bras Pneumol. 2007;33(5):519-526. https://doi.org/10.1590/ S1806-37132007000500006

PMid:18026649

[6]. Beyerle, Jeanne Monique PA-C, ATC Spirometry for the primary care provider, Journal of the American Academy of PAs: December 2014;27(12):28-34. https://doi.org/10.1097/01.JAA. 0000455647. 12048.9f PMid:25417663

[7]. Bharati Mehta, Kunal Garg, Sneha Ambwani, Bharti Bhandari, Om Lata Bhagat. Peak Expiratory Flow Rate: A Useful Tool for Early Detection of Airway Obstruction in School Children. Open Medicine Journal, 2016;3:159-165.

https://doi.org/10.2174/1874220301603010159

[8]. Retory Y, Niedzialkowski P, de Picciotto C, Bonay M, Petitjean M. New Respiratory Inductive Plethysmography (RIP) Method for Evaluating Ventilatory Adaptation during Mild Physical Activities. PLoS One. 2016;11(3):e0151983.

https://doi.org/10.1371/journal.pone.0151983 PMid:27008313 PMCid:PMC4805261

[9]. Hafke-Dys H, Brêborowicz A, Kleka P, Kociñski J, Biniakowski A (2019) The accuracy of lung auscultation in the practice of physicians and medical students. PLOS ONE 14(8): e0220606.

https://doi.org/10.1371/journal.pone.0220606 PMid:31404066 PMCid:PMC6690530

[10]. Test M, Shah SS, Monuteaux M, Ambroggio L, Lee EY, Markowitz RI, Bixby S, Diperna S, Servaes S, Hellinger JC, Neuman MI, Chest Radiograph Interpretation. J. Hosp. Med 2013;7;359-364.

https://doi.org/10.1002/jhm.1991

PMid:23184766 
R. Vinodh Rajkumar. BREATHING RATE/RHYTHM EVALUATION ASCERTAINS TOTAL HEALTH (BREATH): THE PULMONARY PANACEA.

[11]. Tyler J.Paradis, Jennifer Dixon, Brandon H.Tieu. The role of bronchoscopy in the diagnosis of airway disease. J.Thorac Dis.2016 Dec;8(12): 3826-3837. https://doi.org/10.21037/jtd.2016.12.68 PMid:28149583 PMCid:PMC5227188

[12]. Winokur RS, Pua BB, Sullivan BW, Madoff DC. Percutaneous lung biopsy: technique, efficacy, and complications. Semin Intervent Radiol. 2013;30(2):121-127.

https://doi.org/10.1055/s-0033-1342952

PMid:24436527 PMCid:PMC3709987

[13]. Bhatt SP. Generic Respiratory Symptoms and Branded Lung Diseases. Same Difference?. Am J Respir Crit Care Med. 2018;197(12):1521-1523. https://doi.org/10.1164/rccm.201801-0191ED PMid:29420052 PMCid:PMC6006409

[14]. Keir E. J. Philip, Emma Pack, Valentina Cambiano, Hannah Rollmann, Simon Weil, and James O'Beirne. The accuracy of respiratory rate assessment by doctors in a London teaching hospital: a crosssectional study. J Clin Monit Comput. 2015; 29(4): 455-460. https://doi.org/10.1007/s10877-0149621-3 PMid:25273624 PMCid:PMC4487351

[15]. Sandy Rolfe. The importance of respiratory rate monitoring. British Journal of Nursing, 2019;28(8). https://doi.org/10.12968/bjon.2019.28.8.504 PMid:31002547

[16]. Michelle A Cretikos, Rinaldo Bellomo, Ken Hillman, Jack Chen, Simon Finfer, Arthas Flabouris. Respiratory rate: The neglected vital sign. The Medical journal of Australia, 2008, 188(11):657-9. https:// doi.org/10.5694/j.1326-5377.2008.tb01825.x PMid:18513176

[17]. Ottestad W, Søvik S. COVID-19 patients with respiratory failure: what can we learn from aviation medicine? [published online ahead of print, 2020 Apr 18]. Br J Anaesth. 2020;S00070912(20)30226-9.

https://doi.org/10.1016/j.bja.2020.04.012

PMid:32362340 PMCid:PMC7165289

[18]. R. Vinodh Rajkumar. Prevalence of Outward Deviation of Feet in Human Gait: A Non-participant Observation. Int J Physiother Res 2020;8(1):3378-3387. https://doi.org/10.16965/ijpr.2020.101

[19]. Sathiyamoorthi S, Anand DP, Muthunarayanan L. Is Master Health Checkup the Answer to Tackle the Rising Non-Communicable Disease Burden in India? - A Cross-Sectional Study. J Lifestyle Med. 2019;9(2):111-118.

https://doi.org/10.15280/jlm.2019.9.2.111

PMid:31828029 PMCid:PMC6894444

[20]. Lalande, L., Bambling, M., King, R., \& Lowe, R. Breathwork: An additional treatment option for depression and anxiety? Journal of Contemporary Psychotherapy, 2011;42:113-119.

https://doi.org/10.1007/s10879-011-9180-6

[21]. Rudrappa M, Modi P, Bollu PC. Cheyne Stokes Respirations. [Updated 2020 Jun 12]. In: StatPearls [Internet]. Treasure Island (FL): StatPearls Publishing; 2020 Jan. Available from:

https://www.ncbi.nlm.nih.gov/books/NBK448165/
[22]. Guri A, Scheier E, Adi M, et al. Biot's breathing associated with acute bacterial meningitis in a child. Case Reports 2018.

https://doi.org/10.1136/bcr-2018-225774 PMid:29960974 PMCid:PMC6040499

[23]. Minagar, A., \& Weiner, W. J. Adolf Kussmaul and His Respiratory Sign. Journal of Medical Biography, 2001;9(3):181-183. https://doi.org/10.1177/ 096777200100900311 PMid:11466520

[24]. Gallo de Moraes A, Surani S. Effects of diabetic ketoacidosis in the respiratory system. World J Diabetes. 2019;10(1):16-22.

https://doi.org/10.4239/wjd.v10.i1.16 PMid:30697367 PMCid:PMC6347653

[25]. Drain CB. Physiology of respiratory system related to anesthesia. CRNA. 1996;7:163-80

[26]. Patwa A, Shah A. Anatomy and physiology of respiratory system relevant to anaesthesia. Indian J Anaesth. 2015;59(9):533-541. https://doi.org/10.4103/0019-5049.165849 PMid:26556911 PMCid:PMC4613399

[27]. Tobin MJ. Basing Respiratory Management of COVID-19 on Physiological Principles. Am J Respir Crit Care Med. 2020;201(11):1319-1320. https://doi.org/10.1164/rccm.202004-1076ED PMid:32281885 PMCid:PMC7258630

[28]. Patel S, Sharma S. Respiratory Acidosis. [Updated 2020 Jun 24]. In: StatPearls [Internet]. Treasure Island (FL): StatPearls Publishing; 2020 Jan-. Available from: https://www.ncbi.nlm.nih.gov/books/ NBK482430/

[29]. NICE CG50: Recognition of and response to acute illness in adults in hospital. National Institute of Clinical Excellence. http://www.nice.org.uk/CG50 (2007).

[30]. Van Dam MN, Fitzgerald BM. Pulsus Paradoxus. [Updated 2020 May 17]. In: StatPearls [Internet]. Treasure Island (FL): StatPearls Publishing; 2020 Jan-. Available from: https://www.ncbi.nlm.nih.gov/ books/NBK482292/

[31]. Urell, C., Emtner, M., Hedenstrom, H. et al. Respiratory muscle strength is not decreased in patients undergoing cardiac surgery. J Cardiothorac Surg 2016;11:41. https://doi.org/10.1186/s13019-0160433-z PMid:27036318 PMCid:PMC4815249

[32]. Katz, S., Arish, N., Rokach, A. et al. The effect of body position on pulmonary function: a systematic review. BMC Pulm Med 2018;18:159.

https://doi.org/10.1186/s12890-018-0723-4 PMid:30305051 PMCid:PMC6180369

[33]. Westerdahl E, Lindmark B, Bryngelsson I, Tenling A. Pulmonary function 4 months after coronary artery bypass graft surgery. Respir Med. 2003;97(4):31722. https://doi.org/10.1053/rmed.2002.1424 PMid:12693792

[34]. Xiaoneng Mo, Wenhua Jian, Zhuquan Su, Mu Chen, Hui Peng, Ping Peng, Chunliang Lei, Shiyue Li, Ruchong Chen, Nanshan Zhong. Abnormal pulmonary function in COVID-19 patients at time of hospital discharge. European Respiratory Journal 2020. https://doi.org/10.1183/13993003.01217-2020 PMid:32381497 PMCid:PMC7236826 
[35]. Grimby G, Fugl-Meyer AR, Blomstrand A. Partitioning of the contributions of rib cage and abdomen to ventilation in ankylosING SPONDYLITIS. Thorax. 1974;29(2):179-184.

https://doi.org/10.1136/thx.29.2.179

PMid:4831523 PMCid:PMC470125

[36]. R.Vinodh Rajkumar. Lungeometry - Geometrical Investigation of Lunge. International Journal of Physiotherapy and Research 2015;3(1):855-862.

https://doi.org/10.16965/ijpr.2014.703

[37]. Jamie E. Crockett, Craig S. Cashwell, Jodi L. Tangen, K. Hridaya Hall, and J. Scott Young. Breathing Characteristics and Symptoms of Psychological Distress: An Exploratory Study. Counseling and Values. April 2016;61.

https://doi.org/10.1002/cvj.12023

[38]. Ma X, Yue ZQ, Gong ZQ, et al. The Effect of Diaphragmatic Breathing on Attention, Negative Affect and Stress in Healthy Adults. Front Psychol. 2017;8:874. https://doi.org/10.3389/fpsyg.2017.00874 PMid:28626434 PMCid:PMC5455070

[39]. Bonilha AG, Onofre F, Vieira ML, Prado MY, Martinez JA. Effects of singing classes on pulmonary function and quality of life of COPD patients. Int J Chron Obstruct Pulmon Dis. 2009;4:1-8.

https://doi.org/10.2147/COPD.S4077

[40]. R. Surekha, R. Archana, B. Vijayalakshmi. Effect of regular dance practice on pulmonary functions and respiratory efficiency in female bharatanatyam dancers - A pilot study. International Journal of Research in Pharmaceutical Sciences. 2018; 9(4):12681273.

[41]. Michael A. Roman, Harry B. Rossiter, Richard Casaburi. Exercise, ageing and the lung. European Respiratory Journal 2016;48:1471-1486. https://doi.org/10.1183/13993003.00347-2016 PMid:27799391
[42]. Iwasaki A, Medzhitov R. Control of adaptive immunity by the innate immune system. Nat Immunol. 2015 Apr; 16(4):343-53.

https://doi.org/10.1038/ni.3123 PMid:25789684 PMCid:PMC4507498

[43]. Gomes-Filho IS, Passos JS, Seixas da Cruz S. Respiratory disease and the role of oral bacteria. J Oral Microbiol. 2010;2:10.

https://doi.org/10.3402/jom.v2i0.5811 PMid:21523216 PMCid:PMC3084574

[44]. Paju S, Scannapieco FA. Oral biofilms, periodontitis, and pulmonary infections. Oral Dis. 2007;13(6):508-512. https://doi.org/10.1111/ j.1601-0825.2007.01410a.x PMid:17944664 PMCid:PMC2258093

[45]. Parameswaran K, Todd DC, Soth M. Altered respiratory physiology in obesity. Can Respir J. 2006;13(4):203-210. https://doi.org/10.1155/2006/834786 PMid:16779465 PMCid:PMC2683280

[46]. Krina Chheda, Jaimala Shetye, Amita Mehta. Comparison of spirometric pulmonary function in subjects with apple and pear shape fat distribution. Int J Physiother Res 2020;8(3):3484-3490. https://doi.org/10.16965/ijpr.2020.133

[47]. R.Vinodh Rajkumar. Endomorphy dominance among non-athlete population in all the ranges of body mass index. International Journal of Physiotherapy and Research 2015;3 (3):1068-1074. https://doi.org/10.16965/ijpr.2015.139

[48]. R.Vinodh Rajkumar. Epidemiological Intersection: The Revelation of Covid - 19 Pandemic. Int J Physiother Res 2020;8(2):3438-42. https://doi.org/10.16965/ijpr.2020.126

[49]. R. Vinodh Rajkumar. Gravitational Torque Deficiency Syndrome (GTDS): A Prospective Clinical Terminology - Part 1. Int J Physiother Res 2016;4(5):16681678. https://doi.org/10.16965/ijpr.2016.161

[50]. Prem Shankar Srivastava. Spiritual Intelligence: An Overview. International Journal of Multidisciplinary Research and Development. 2016;3(3):224-227.

How to cite this article:

R. Vinodh Rajkumar. BREATHING RATE/RHYTHM EVALUATION ASCERTAINS TOTAL HEALTH (BREATH): THE PULMONARY PANACEA. Int J Physiother Res 2020;8(5):3609-3619. DOI: 10.16965/ijpr.2020.161 